\title{
CONSTRUINDO UMA SOLUÇÃO E REALIZANDO UM PROTOCOLO REABILITADOR
}

Lidiane Cunha AFONSO, Patrícia Marcoccia SOUZA, Renato Leite ROSA

As condutas clínicas devem ser construídas de maneira protocolar. Isto posto, a entrevista e a anamnese do paciente desempenham um papel preponderante no tratamento a ser instituído. Em movimento contínuo deve-se proceder a coleta de dados documentais, como por exemplo, utilizando uma documentação radiográfica digitalizada em alta resolução; realizando uma documentação digital de imagens estáticas e dinâmica, por meio de filmagem, focada em dados da entrevista; modelos em gesso especial para arquivo; modelos em gesso pedra para montagem em ASA; registros oclusais intra orais na posição de Relação Cêntrica $(R C)$ e modelos encerados após montagem em ASA. Com o auxílio destes dados, elaboramos modelos de possibilidades de tratamento enfatizando os desvios da normalidade estética e atendendo aos anseios do paciente. $O$ modelo escolhido é aprofundado e traduzido em plano de tratamento e orçamento. O presente trabalho tem por objetivo descrever de maneira apropriada a aplicação de um protocolo de reabilitação estético funcional em um caso complexo. Concorreram para sua realização várias especialidades odontológicas e suporte psicológico.

Palavras-chave: reabilitação, planejamento, anamnese, fotografia. 